\title{
Seeing Is Believing: Mathematics Visualization In Economics Education
}

Daniel K.N. Johnson, (E-mail: djohnson@ColoradoCollege.edu), Colorado College

\begin{abstract}
Visualization through the use of physical objects is an important method that instructors can use to convey and solidify an understanding of economic principles in their novice students of economics. This paper outlines three simple examples which have been successful in the classroom, each taking a question that students frequently ask --- why we build models, what a model looks like, and what we learn from a model --- and answering them with images of airplanes, watermelons and windows.
\end{abstract}

\section{INTRODUCTION}

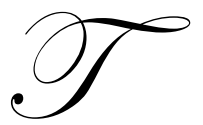

he most powerful lessons economists teach are those which students remember. They are the lessons which students are able to see in their mind's eye years after their last economics lecture, and which they can apply to their lives and professions. Visualization of economic concepts through the use of physical objects is an important, and underutilized, method that teachers can use to convey abstract economic concepts with a permanence that lends power to their economic arguments, a method which will help students to understand and remember the concepts more fully.

A wide literature already espouses the value of visual activity in the learning of quantitative or mathematical material. For example, DiBiase (1990) has explained the role that visualization can play in the exploration of new material, the confirmation of existing results, the synthesis of different theories, and the presentation of final results to others. MacEachren (1994) has done the same for geography and cartography, while a rapidly expanding literature on geographical imaging systems (GIS) software and the insights offered by visualization makes the same point for social sciences in general (see for example, Kraak and Ormeling 1996, Slocum 1999). Edward Tufte's work $(1983,1990,1997)$ spans all of the social and physical sciences in emphasizing the benefits of "escaping flatland", or the need to expand beyond the tendency to view information or theory as unidimensional.

Eugene Ferguson (1992) makes an interesting argument for visualization by pointing out the historical importance of objects or physical models in architecture, construction and engineering. Not only were visual representations and physical models essential in conveying knowledge but also in evaluating and improving existing techniques or theory. Take for example, the continuing requirement that patent applications are frequently required to submit technical drawings in order to prove a degree of novelty over predecessors.

While examples abound, this paper outlines three simple examples which have been successful in the classroom in an introductory undergraduate economics level. The examples have been chosen to respond to three questions that students frequently ask --- why we build models, what a model looks like, and what we learn from a model.

The following three sections address each of the examples in turn. 


\section{EXAMPLE I: AIRPLANES (OR "WHY ECONOMISTS BUILD MATHEMATICAL MODELS")}

At some point in an introductory class (and often later, if the student has not been exposed to a suitable explanation earlier), an instructor will be asked to explain why economists build models. A visual example helps to convey and solidify the fundamental understanding that economists use models to identify and describe key relationships in a world that consists of a complex interrelated web of relationships. It also allows students to understand what constitutes a good model, and empowers them to test their own models for unrealistic assumptions.

While textbooks often present a map as an example of a model popularly used in society, consider instead the use of three model airplanes ${ }^{1}$ : a craft kit built to scale, a paper airplane, and a printout of the seating plan from a passenger jet (available from websites for most major airlines). The contrast is striking, and can be used to make the point that the same concept can be modeled in a number of ways, with differing implications and more or less reliable results, depending on the model's purpose. Given a moment to compare each model to the underlying reality of a real airplane, students can focus on the key assumptions that constitute each model, and can suggest questions or hypotheses testable with each to ensure realistic results.

The craft kit assumes that scale but not absolute size is important, and that materials, mechanical elements and the properties of flight are unimportant. If the intent of the model is to convey the impact of shape on wind resistance, the model is perhaps acceptable. If the intent of the model is to describe the dynamics of sustained flight, the assumptions are unacceptable.

The paper airplane similarly assumes that materials and mechanical elements are unimportant, but instead asserts that the property of flight is essential while shape and scale are not. From some viewpoints it is a very "heroic" model, but if the intent of the model is to describe the effect of wind patterns on gliding direction, it is undeniably superior to the first model. Finally, the seating plan assumes that even the three-dimensional nature of an airplane is unimportant, and that the external appearance of reality can be cut away to reveal the interior workings of the issue. This is the only useful model if the purpose is to place emergency doors at positions which allow the quickest escape routes to a maximum number of passengers.

From this simple discussion, students learn the importance of assumptions, and the critical exercise of comparing the assumptions against the purpose of the model before declaring the model to be "unrealistic".

\section{EXAMPLE II: WATERMELONS (OR "WHAT A MATHEMATICAL MODEL 'LOOKS' LIKE")}

It is essential that economics students understand the relationship between the utility function and indifference curves in order to work through problems with more than a rote understanding of constrained optimization. Utility functions in economics are traditionally assumed quasi concave in two variables (e.g. $U(x, y)=$ $\mathrm{X}^{1 / 2} \mathrm{y}^{1 / 2}$ ) for the economic properties that the form implies, and indifference curves are the level lines or isovalue lines of the function, joining all $(\mathrm{x}, \mathrm{y})$ points of equal utility value. A linear budget constraint is usually imposed (e.g. $3 x+4 y=12)$ to indicate which $(x, y)$ points are feasible. The economic goal is to maximize utility subject to feasibility, a simple constrained optimization problem in three dimensions. While the mathematics initially confuses many students, a simple visualization example using a quarter of a watermelon, a cutting board and a cleaver performs a demonstration of the utility model extremely clearly and humorously.

In preparation for this demonstration, use tape to indicate a set of axes on the cutting board, labeling them "x" and "y" or with two products for illustration. Place the quarter melon with the long flat side face down on the board and mark indifference curves using masking tape or a series of colored thumbtacks to trace level lines at intervals of one inch (two inches, three inches, etc.) from the face. Covering the entire marked melon with plastic wrap keeps the demonstration from becoming too messy in the classroom.

After introducing utility theory and explaining the concept of indifference curves model. Place the melon face down on the board with the wide end facing away from the origin. ${ }^{2}$ Allow the students to see that the indifference curves are parallel to each other and to the cutting board. The surface of the melon now becomes the 
value of utility and height away from the cutting board can clearly be seen as a higher surface of the melon. ${ }^{3}$

Now a quick twist of the melon and board ninety degrees to place the board in a vertical position and the top of the melon in the class's view inevitably brings gasps of surprise as they realize that the indifference curves are quasi-convex, increasing away from the origin, exactly as indicated earlier by the theory.

The cleaver can now make an entrance as the budget constraint, perpendicular to the cutting board and slashing down through the melon at an angle decreed by relative prices. After making a cut at a tangency point, show the severed piece of melon to the class, indicating that this section is the only part of the melon possible, given the current budget constraint. It will be obvious that the highest point of the piece is located precisely where it was tangent to an indifference curve.

This has become a favorite lecture, both for me and for my students, earning the name "Watermelon Week" among some groups. Most importantly, students remember the demonstration later when asked to maximize a function, can speak intelligently about the assumptions involved (including quasi-convexity) and can visualize what their solution means before they begin to mathematize the answer.

\section{EXAMPLE III: WINDOWS (OR "WHAT ECONOMISTS LEARN FROM A MODEL")}

One of the most difficult (yet important) topics to convey in any class is the importance of the result obtained from a model. When engaged in discussion about taxation, one of the key results is a drop in efficiency, or deadweight loss. Again, visualization converts a purely mathematical concept of foregone potential into a memorable, tangible result.

By this point in the class, students are all familiar with supply and demand functions, and the simple linear algebra required to find the intersection point, or equilibrium. Taxation shifts the supply curve vertically, because suppliers will now ask a higher price for every unit of the good, knowing that tax revenues will have to be subtracted from the sales price for remittance to the government. The surprising result (for most students) is that this results in less production and less consumption, with a specific dollar value that can be placed on the foregone product calculated as area on an x-y plane. Sadly, "unrealized potential" is a concept which many college students have difficulty considering as a loss to society. The following example drives the point home.

At both Yale University and Wellesley College (as well as a number of other schools), the campus includes examples of architecture copied directly from British campuses. When students are asked about the reason for the strange presence of bricked- up windows on campus, usually their answer revolves back to this practice of copying. However, few of them can offer the reason that British campuses have bricked-up windows. In 1749, Britain enacted a window tax, designed as a progressive tax that would be easily administered. Records indicate that by 1766 tax evasion was already a serious problem, as "owners both in town and country began to disfigure their houses immediately... by blocking up their windows" (Camperdown, 1848). As a result, the British legislature began a slow phasing-out of the window tax beginning in 1823. A similar tax was briefly imposed in the American colonies, so bricked-up windows might have occurred in the US even in the absence of architectural copying, given enough time.

The intensely visual example offers an opportunity to discuss the issue of progressivity in taxes, as well as the costs of tax collection. Best of all, the bricked-up window becomes a perfect visual analogy to the darkened triangle of deadweight loss in the standard partial equilibrium graph. There are fewer windows to enjoy, and there is no tax revenue on a non-existent window, yet buyers were willing and able to purchase them (and did, before bricking them over), and sellers were willing and able to produce them (and did, they were bricked over).

Other visual examples abound, if the example of bricked-up windows is not readily accessible to students. For example, the island of Nantucket (as part of the Commonwealth of Massachusetts) had a room tax on all property during its whaling heyday. The evidence is still available, as tours through the whaling captains' homes point out the interesting case of rooms with closets wallpapered shut (since closets were counted as rooms) and freestanding armoirs replacing them but reducing useable floorspace. Once again, the unused space is a perfect visual link to deadweight loss. 


\section{CONCLUSION}

Visualization is an important element of the learning and teaching process, and often provides a critical link between abstract mathematical concepts and the world in which students live. The use of visual tools, from airplanes to melons to windows, can be incredibly productive in sending students a message about the usefulness and widespread applicability of economics. Visual stimuli can help not only in the learning of economics, but in the retention and application of that knowledge well after our students graduate.

\section{ACKNOWLEDGEMENTS:}

Special thanks to David Popp, who shared the idea of the first example in this paper and who encouraged me to write these examples down, and to my students at Harvard University, Yale University, Wellesley College and Colorado College who have responded so enthusiastically to visualization in class. Thanks to a Mrachek Fellowship for the release time that enabled the final writing and editing of this work.

\section{ENDNOTES}

1. Thanks to David Popp for sharing a version of this example with me, and with his students.

2. Introduce it as a "garden variety" utility function if you wish.

3. $\quad$ "Living high on the watermelon" becomes an appropriate goal in life.

\section{REFERENCES}

1. Camperdown, Adam Duncan-Haldane. A Speech delivered in the House of Commons on Thursday, February 24,1848 on a motion for leave to bring in a bill for the repeal of the window tax. J. Hatchard, London, 1848.

2. DiBiase, David. Visualization in the Earth Sciences. Earth and Mineral Sciences, Vol 59(2), 1990. p.13-18.

3. Ferguson, Eugene S. Engineering and the Mind's Eye. MIT Press, 1992.

4. Kraak, M.J. and F.J. Ormeling. Cartography: Visualization of Spatial Data. Longman Press, 1996.

5. MacEachren, Alan M. Visualization in Modem Cartography: Setting the Agenda, Visualization in Modem Cartography. Pergamon Press, 1994.

6. $\quad$ Slocum, Terry. Thematic Cartography and Visualization._Prentice Hall, 1999.

7. Tufte, Edward. Envisioning Information._Graphics Press, 1990.

8. Tufte, Edward. The Visual Display of Quantitative Information. Graphics Press, 1983.

9. Tufte, Edward. Visual Explanations: Images and Quantities, Evidence and Narrative. Graphics Press, 1997.

10. Zimmerman, Walter and Steve Cunningham, editors. Visualization in Teaching and Learning Mathematics. Mathematical Association of America, 1991. 